Copyright (C) 2006 Wiley Periodicals, Inc., A Wiley Company

\title{
In vitro and in vivo (cyto)toxicity assays using PVC and LDPE as model materials
}

\section{E. A. E. Van Tienhoven $1 *$, D. Korbee 1, L. Schipper 1, H. W. Verharen 2, W. H. De Jong 2}

1Centre for Biological Medicines and Medical Technology, National Institute for Public Health and the Environment, P.O. Box 1, 3720 BA Bilthoven, the Netherlands

2Laboratory for Toxicology, Pathology and Genetics, National Institute for Public Health and the Environment, P.O. Box 1, 3720 BA Bilthoven, the Netherlands email: E. A. E. Van Tienhoven (esther.van.tienhoven@rivm.nl)

*Correspondence to E. A. E. Van Tienhoven, Centre for Biological Medicines and Medical Technology, National Institute for Public Health and the Environment, P.O. Box 1, 3720 BA Bilthoven, the Netherlands

\section{ABSTRACT}

The choice for a biomaterial is partly based on the outcome of (cyto)toxicity assays. The rationales behind the selection of certain parameters, such as cell lines, controls, and animals, were evaluated using a positive and a negative control, and one experimental sample designed to induce intermediate toxicity. Extraction and direct contact assays were performed using human epidermal keratinocytes and mouse fibroblasts and mouse epithelial cells. Cell survival was measured with the tetrazolium salt (MTT) reduction assay. In addition, local implantation studies were performed in mice and rats. The positive control induced a high degree of toxicity in all in vitro tests performed, indicating that the toxicity observed in the direct contact assay was due to in situ extraction of toxic components. In the direct contact assay the negative control tested on the mouse fibroblasts resulted in a significant reduction of cell survival. No decrease in cell survival was found using the experimental sample. Subcutaneous implantation studies in mice showed that the positive control material induced a severe degeneration in mice. However, in rats just minimal alterations were noted. The experimental material induced moderate responses only in mice. Our results indicate that the direct contact assay provides limited additional information on the cytotoxicity of materials if certain limitations are not taken into account. For the in vivo implantation assay mice were superior to rats in detecting local toxic responses. (c) 2006 Wiley Periodicals, Inc. J Biomed Mater Res, 2006 


\section{INTRODUCTION}

One of the important prerequisites for the clinical usefulness of biomaterials is a high level of biocompatibility. Biocompatibility refers to the ability of the material to perform its intended function without eliciting any undesirable local or systemic effects in the host.[1] Local leakage of toxic substances can result in cell damage and death, which will result in the recruitment of a variety of cells to the site of the implantation. Although the implantation itself induces tissue damage, for biocompatible implants a steady state will be reached during the restoration process, facilitating a successful performance of the implant.[2] In contrast, continuous or prolonged leakage of toxic substances will induce a persisting inflammation. This will interfere with the successful performance of the implant. To avoid such adverse effects, the potential toxicity of a biomaterial should be evaluated before clinical use in vitro and in vivo. In recent years, driven by the progress of tissue engineering,[3][4] many papers described the selection of biomaterials based on cytotoxicity tests.[5-8] Additionally, the selection can be based on local implantation tests.[9][10] A series of standards, the EN/ISO 10993 series, has been developed to consider and select relevant tests for the biological evaluation of biomaterials.[11] Part 5 of this series focuses on cytotoxicity assays describing the many possibilities for endpoint measuring, cell line selection, and sample selection.[12] One of the limitations of a short-term cytotoxicity test is that it measures the effect only during the first 12-24 $\mathrm{h}$ after exposure to a toxic substance. However, many biological reactions in vivo are rather complex and continue beyond $24 \mathrm{~h}$. This can be investigated with implantation studies. Part 6 of the EN/ISO 10993 deals with these local effects after implantation.[13] Although both standards describe the possibilities in detail, it is still a difficult task for the investigator to rationalize the choices for each relevant parameter. These choices can affect the outcome of the test, and thus the acceptance or rejection of the biomaterial for clinical use.[14-18]

To discuss some of the rationales behind the selection of parameters, we evaluated the in vitro system using three different cell lines, both in an extraction assay and in a direct contact assay. We used as a negative control sample a low density polyethylene (LDPE), as a positive control sample a poly(vinylchloride) (PVC) recepture stabilized with organo-tin, and one experimental PVC sample designed to induce an intermediate toxicity. In addition, the materials were tested in a local subcutaneous implantation study in mice and rats.

\section{MATERIALS AND METHODS}

\section{Cell lines}

The mouse fibroblast cell lines L929, the mouse epithelial cell line McCoy, and the human epidermal keratinocyte cell line HaCaT were used. The L929 (passage 561) was obtained from the European Collection of Animal Cell Cultures (ECACC), the McCoy cell line (passage 8 ) was kindly provided by L. Berkenbosch and T. Slobbe Solvay Draka, Enkhuizen, the Netherlands, and the HaCaT cell line (passage 43) was kindly provided by Prof. N. Fusenig (German Cancer Institute, Heidelberg, Germany).[19] Cells were incubated at $37^{\circ} \mathrm{C}$ in $5 \% \mathrm{CO} 2$ in humidified air. For the cell lines L929 and McCoy, Dulbecco's modified Eagles culture medium, high glucose with glutamax (DMEM, Gibco, Invitrogen Life Technologies, Breda, the Netherlands) was used. The medium was supplemented with penicillinstreptomycin $(100 \mathrm{U} / \mathrm{mL}-0.1 \mathrm{mg} / \mathrm{mL})$ (SVM, Bilthoven, the Netherlands), $5 \%$ nonessential amino acids (Gibco) and $10 \%$ fetal calf serum (FCS, Gibco). The culture medium used for HaCaT was DMEM with $0.11 \mathrm{~g} / \mathrm{L}$ sodium pyruvate and pyridoxine (Gibco). This medium was supplemented with $10 \%$ FCS, penicillin-streptomycin $(100 \mathrm{U} / \mathrm{mL}-0.1 \mathrm{mg} / \mathrm{mL})$ and L-glutamine $(0.2 \mathrm{~mol} / \mathrm{L})(\mathrm{SVM})$. When cells reached $80 \%$ confluence, they were subcultured into another flask by trypsinization with a 
trypsin $(0.25 \%)$-EDTA $(0.03 \%)$ solution. Cell growth and confluence were examined under a phase contrast microscope.

\section{Test specimens}

As a positive control, a poly (vinylchloride) recepture stabilized with organo-tin was prepared, designated as PVC-Sn. This recepture is known to have a strong cytotoxic effect leading to extensive cell death and lysis, and is commonly used as a positive control for cell death.[11] As a negative control material a low density polyethylene (LDPE) was used (LDPE Exxon LD100 lotnr 1743). In addition, a PVC material was prepared with the aim to induce an intermediate (cyto)toxic response, designated PVC-Exp containing DEHP plasticizer (2:1) and Ca/Zn-based stabilizers. The three materials were kindly provided by $\mathrm{Dr}$. L. Berkenbosch (Solvay Draka, Enkhuizen, the Netherlands). The PVC-Sn and the PVC-Exp were prepared specifically for the purpose of this investigation. Discs of the material, with a thickness of 0.35 and $0.5 \mathrm{~mm}$ respectively, and a diameter of 6 and 10 $\mathrm{mm}$ respectively, were cut for in vitro and in vivo testing. Directly before use, the materials were sterilized by ethanol, washed with PBS, and dried into sterile air in a laminar flow, as recommended by the manufacturer.

Extracts were prepared as described in the ISO standard.[12] The materials were incubated in tissue culture medium without FCS for $24 \mathrm{~h}$ at $0^{\circ} \mathrm{C}, 37^{\circ} \mathrm{C}$, and $70^{\circ} \mathrm{C}$, and for $48 \mathrm{~h}$ and $72 \mathrm{~h}$ at $37^{\circ} \mathrm{C}$. All conditions were applied without stirring. No adjustment of the $\mathrm{pH}$ was necessary. The ratio of outer surface to fluid volume was $8 \mathrm{~cm} 2 / \mathrm{mL}$. As a blank control, extract medium was treated under similar conditions. All extracts were used immediately.

\section{Cytotoxicity assay}

To asses the short-term cytotoxicity of the materials EN/ISO 10993-5 was used.[12] The assay was performed using cells growing in exponential phase. Cells were seeded in a 96 wells tissue culture plate (Costar, Badhoevedorp, the Netherlands) at a concentration of $2 \times 104$ cells/well in a medium volume of 100 L. After overnight cell culture, tissue culture medium was discarded and the extraction fluids were added. During incubation with the extracts the FCS concentration was $5 \%$. This percentage was chosen to prevent interference by serum in the assay. The incubation was performed for $24 \mathrm{~h}$ at $37^{\circ} \mathrm{C}$. The cell viability was determined as described below.

The direct contact assay was performed either by seeding cells on a disc of the material $(0.56 \mathrm{~cm} 2)$ covering the bottom of a tissue culture well in a 96-wells plate, or by placing a disc on an established confluent monolayer in the center of each well. For the latter method, cells were seeded in a 24-wells plate at a concentration of $1.3 \times 105$ cells/well. The sample covers approximately oneseventh of the cell layer surface. After $24-\mathrm{h}$ incubation at $37^{\circ} \mathrm{C}$, cell viability was determined as described later.

\section{Determination of cell viability}

Tetrazolium (MTT, $1 \mathrm{mg} / \mathrm{mL}$ in medium) was used to determine cell viability.[20] In the MTT assay the metabolic activity is determined as a measure for cytotoxicity. Briefly, after incubation with the specimen MTT was added. After $3 \mathrm{~h}$ cells were washed with PBS. Dimethylsulfoxide (DMSO) was added for

solubilization. The solution was homogenized by shaking the plates for $3 \mathrm{~min}$. The homogenized solutions were transferred to another 96-wells plate. The optical density (OD) was read at $540 \mathrm{~nm}$ on a multiwell microtiter plate photospectrometer (Titertek Multiskan, Flow Laboratories, Lugano, Switzerland). All assays were performed in triplicate. The OD of medium without cells was subtracted as background. The results were presented as reduction of metabolic activity in percentage when compared to control cells cultured in medium only $(100 \%)$. 


\section{Statistical analysis}

Results were expressed as mean \pm standard error of the mean. Comparisons between groups were performed with a paired two-tailed distribution t-test.

\section{In vivo implantation}

WU rats and BALB/c mice, aged 6-8 weeks, were used to test subchronic local effects. They were obtained from the animal breeding facility of the institute (RIVM, Bilthoven, the Netherlands). National regulations for the care and use of laboratory animals have been observed. Animals were bred under SPF conditions and barrier maintained during the experiment. Specimens were subcutaneously implanted under inhalation anesthesia $(\mathrm{O} 2, \mathrm{NO} 2$, and halothane $2 \%)$. Post surgery, the animals received once buprenorfin subcutaneously (Temgesic, Schering-Plough BV, Utrecht, the Netherlands). Specimens of LDPE, PVC-Sn, and PVC-Exp were implanted with a rotating schedule on the dorsal flank of the animals. Each animal received three samples. The animals were euthanized after 3,7 , or 98 days by $\mathrm{CO} 2$ and $\mathrm{O} 2$ and implants were removed. For each specimen and each time point investigated, six samples were implanted. After removal the implants were divided in half and fixed for at least one week in a mixture of commercial formaldehyde (4\%) and glutaraldehyde (1\%). Tissue samples were routinely embedded in 2-hydroxyethylmethacrylate using infiltration and embedding solutions (Technovit 7100, Hereus Kulzer GmbH, Wehrheim, Germany). Tissue sections of 1-2 m were prepared, and stained with toluidin blue $(0.1 \%)$. The sections were evaluated by light microscopy, and tissue reactions and/or infiltrates were scored semiquantitatively as follows: 1 , minimal; 2, slight; 3, moderate; 4, marked; and 5, severe.

\section{RESULTS}

\section{Toxicity test by using extracts}

The materials were extracted for $24 \mathrm{~h}$ at $37^{\circ} \mathrm{C}$ at a surface/volume ratio of 8 $\mathrm{cm} 2 / \mathrm{mL}$ in medium containing no FCS. The extracts were tested in the in vitro toxicity assay using three different cell lines. No cytotoxicity was observed with the negative control LDPE for any of the cell lines and a high degree of cytotoxicity almost up to $100 \%$ was consistently observed with the positive control material (Fig. 1). Using the extract of PVC-Exp no toxicity was observed in any of the cell lines. Increasing the extraction time to $72 \mathrm{~h}$ and/or increasing the extraction temperature to $70^{\circ} \mathrm{C}$ did not result in cytotoxic responses of the negative control or the experimental material (data not shown). By diluting the extracts of the positive control material, the cytotoxicity showed a dose response curve (data not shown). No difference in sensitivity was observed between the different cell lines. 


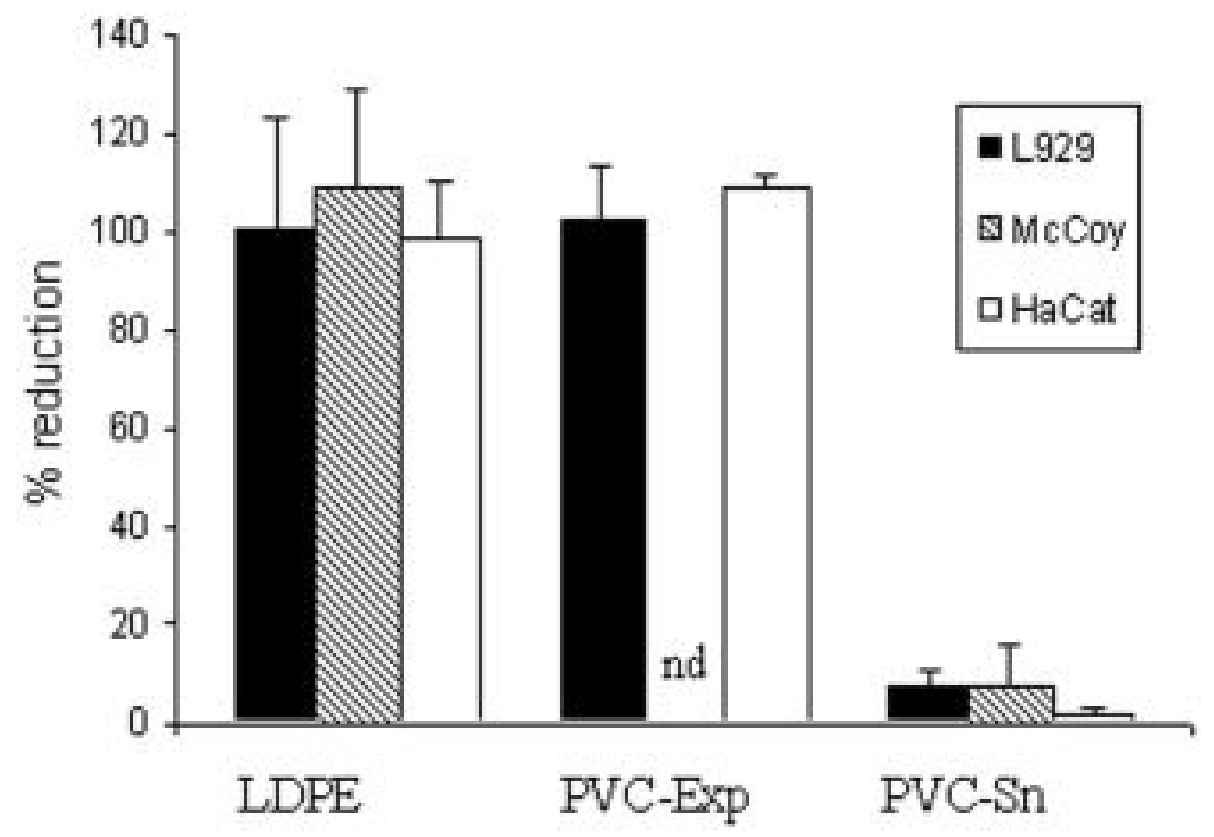

Figure 1. Cytotoxicity of extracts of biomaterials tested on three different cell lines. The results are presented as reduction of metabolic activity in percentage when compared with the metabolic activity of the control (cells without extracts of materials, 100\%) \pm the standard deviation. Each experiment has been performed at least two times. nd $=$ not determined.

[Normal View 26K | Magnified View 50K]

\section{Direct contact toxicity test}

Extraction tests give valuable information on the cytotoxicity of extractable agents. However, low amounts of toxic agents could be undetectable because of the effects of dilution, while toxicity could still occur in the microenvironment between cells and material. To analyze such activity, direct contact tests were employed. Discs were placed into a 96-wells plate and subsequently cells were added. As shown in Table IA, the PVC-Exp resulted in a reduction in metabolic activity for the L929 and the HaCaT cell lines as compared with cells growing in the absence of test material. Unexpectedly, a reduction was also observed for the negative control material using the cell line L929 (52 $\pm 13 \%$ ). In contrast, the HaCat cell line showed no reduced metabolic activity for the negative control (96 $\pm 18 \%)$. For both cell lines, no significant difference was detected between the negative control material and the PVC-Exp. The PVC-Sn showed, as expected, a significant difference as compared with the negative control group.

Table 1. Direct Contact Assays ${ }^{a}$

\begin{tabular}{lcc}
\hline \multicolumn{4}{c}{ L929 } & McCoy & HaCaT \\
\hline A: cells seeded on material & & \\
LDPE $52 \pm 13(n=6)$ & nd & $96 \pm 18(n=4)$ \\
PVC-Exp $75 \pm 4(n=2)$ & nd & $66 \pm 25(n=4)$ \\
PVC-Sn $3 \pm 1(n=2)^{*}$ & nd & $5 \pm 5(n=4)^{*}$ \\
B: material on cells & & \\
LDPE $97 \pm 3(n=2)$ & $96 \pm 8(n=3)$ & $107 \pm 13(n=2)$ \\
PVC-Exp $86 \pm 16(n=2)$ & $100 \pm 9(n=3)$ & $102 \pm 13(n=3)$ \\
PVC-Sn $26 \pm 18(n=2)^{*}$ & $27 \pm 13(n=4)^{*}$ & $19 \pm 3(n=3)^{*}$ \\
\end{tabular}


a The results are presented as reduction of metabolic activity in percentage when compared to cells cultured in medium alone $(100 \%) \pm$ the standard deviation. The number of times the experiment was performed is given between brackets.

nd $=$ not determined.

$* \mathrm{p}>0.05$ as compared to the negative control LDPE.

The direct contact test was also performed by adding the material to an established cell monolayer covering one-seventh of the monolayer surface. As can be observed in Table I, for all three cell lines both the negative control material and the PVC-Exp showed no reduction in cell metabolic activity. With the positive control material PVC-Sn a level degree of reduction was observed. This reduction was significantly different as compared with the negative control material. The level of cytotoxicity with the positive control in this direct contact assay was in the same order of magnitude as the level of toxicity of this material observed in the extraction assay (Fig. 1).

\section{Implantation in BALB/c mice}

We implanted the three materials in mice and rats and analyzed the implantation sites 3, 7, and 98 days later. Results of the histopathological data are presented in Table II. In mice as expected, with the negative control LDPE a steady state situation with the presence of a mature capsule was observed at day 98 [Fig. $2(A)$. Only a minimal infiltrate was present, either in the capsule or at the implant interface. In general, cells at the interface had a flattened appearance. A local toxic response was observed for the positive control material PVC-Sn a [Fig. $2(C)]$. The implant was completely encapsulated, but there was a severe infiltrate present in the capsule as well as at the implant interface. The cells and tissue near the implant showed severe degeneration and/or necrosis, including the abundant presence of polymorphonuclear neutrophilic granulocytes (PMN). Implantation with the PVC-Exp induced an intermediate response [Fig. 2(B)]. There was a mature capsule accompanied by limited to moderate infiltrate. Cells at the interface were more markedly present with large round nuclei and swollen cytoplasm indicating activated cells of the macrophage lineage. In four implants a slight degeneration and/or necrosis was observed, while in the other two implants a marked degeneration/necrosis was observed.

Table 2. Semiquantitative Evaluation of Local Reactions to Subcutaneous Implants in Mice and Rats

Implantation in Mouse Implantation in Rat

Day 3 Day 7 Day 98 Day 3 Day 7 Day 98

\begin{tabular}{lcccccc}
\hline LDPE & $n=6$ & $n=6$ & $n=6$ & $n=5^{\mathrm{a}}$ & $n=6$ & $n=6$ \\
Cells at interface & $1.2^{\mathrm{b}}$ & 2.7 & 1.8 & 1.8 & 4 & 1.8 \\
Encapsulation & 0 & 1.8 & 4.2 & 0 & 0.2 & 4.7 \\
Protein deposition & 3 & 1.5 & 0 & 2.8 & 1.7 & 0 \\
Degeneration/necrosis & 0.2 & 0 & 0.2 & 0 & 0 & 0 \\
Edema & 3.5 & 1.5 & 0 & 4 & 1.5 & 0 \\
Cellular infiltrate & 2.7 & 2.5 & 1.3 & 2.2 & 2.8 & 1.5 \\
PMN in infiltrate & 1.7 & 1 & 0.2 & 1.2 & 0 & 0.2 \\
& & & & & & \\
PVC-Exp & $n=5^{\mathrm{a}}$ & $n=6$ & $n=6$ & $n=5^{\mathrm{a}}$ & $n=6$ & $n=6$ \\
Cells at interface & 1.6 & 3.5 & 4.2 & 1.4 & 3.5 & 2 \\
Encapsulation & 0 & 1.2 & 4.3 & 0 & 0 & 4.2 \\
Protein deposition & 2.4 & 0 & 0 & 3.6 & 3 & 0 \\
Degeneration/necrosis & 1.2 & 4.2 & 2.2 & 0.2 & 0 & 0.2 \\
Edema & 2.8 & 0 & 1.3 & 3.2 & 1.7 & 0 \\
Cellular infiltrate & 2.6 & 3.8 & 2.2 & 2.6 & 3.3 & 1.2
\end{tabular}




$\begin{array}{lcccccc}\text { PMN in infiltrate } & 1.8 & 3.5 & 2.3 & 1.6 & 0.5 & 0 \\ \text { PVC-Sn } & n=5^{\mathrm{a}} & n=6 & n=6 & n=6 & n=5^{\mathrm{a}} & n=6 \\ \text { Cells at interface } & 0 & 0.8 & 4.5 & 0 & 2.6 & 2.5 \\ \text { Encapsulation } & 0 & 0.5 & 4.2 & 0 & 0 & 3.5 \\ \text { Protein deposition } & 0.8 & 0 & 0 & 3.3 & 2.4 & 0 \\ \text { Degeneration/necrosis } & 4 & 4.3 & 4.3 & 3 & 1.6 & 0.5 \\ \text { Edema } & 3.4 & 0.7 & 0.8 & 3.8 & 3 & 0 \\ \text { Cellular infiltrate } & 2.8 & 3.2 & 4 & 2.8 & 3.4 & 1.8 \\ \text { PMN in infiltrate } & 3.8 & 4.7 & 4.5 & 3.5 & 1.2 & 0\end{array}$

a Six out of 108 implant samples were not suitable for histopathological evaluation.

b Mean histopathological score of reaction, $1=$ minimal, $2=$ slight, $3=$ moderate, $4=$ marked, $5=$ severe.

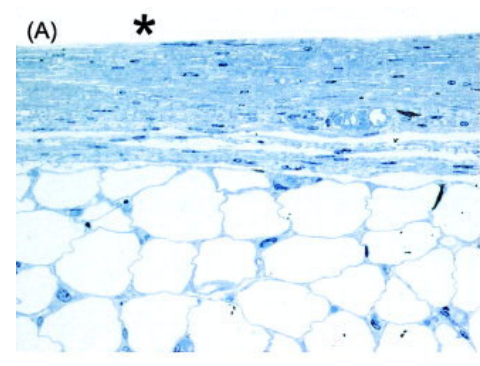

(B)
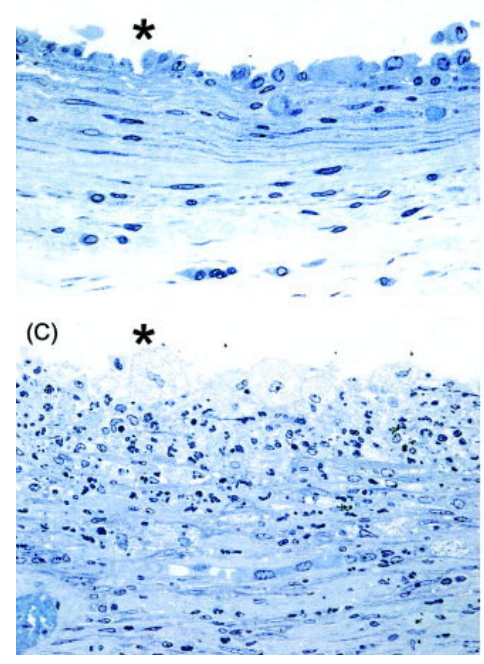

Figure 2. Local subcutaneous reaction at 98 days after implantation. A-C: mouse implanted with LDPE, PVC-Exp, and PVC-Sn respectively. D-F: rat implanted with LDPE, PVC-Exp, and PVC-Sn respectively. Bar represents $50 \mathrm{~m}$, asterisks indicate location of implants. In the mouse, a marked difference between the negative control (LDPE) and the positive control PVC$\mathrm{Sn}$ is present ( $\mathrm{A}$ vs. $C)$. The negative sample (A) shows a mature inactive capsule and the positive control (C) shows local degeneration and

necrosis at the interface accompanied by a severe infiltrate including PMNs. Sample PVC-Exp (B) shows an intermediate response with a mature capsule with swollen cells at the implant interface indicating activation of the cells of the macrophage cell lineage. In the rat, minimal differences between the various local responses are present (D-F).

In all implants proteinaceous exudation, edema, and a cellular infiltrate was observed at day 3 (Table II). These are characteristics of an acute inflammatory response after surgical procedures. However, the positive control PVC-Sn and the experimental material PVC-Exp could be distinguished from the negative control based on degeneration and/or necrosis. This distinction was even more pronounced at day 7. In addition, an abundance of PMNs in the filtrate was observed in the PVC-Sn and PVC-Exp. In some animals this infiltrate extended into the adjacent muscle (Panniculus carnosis). During a reaction to a foreign 
body, macrophages can become activated and can fuse into multinucleated giant cells (MGCs). Therefore, we also investigated the presence of these cells near the implant site at day 98 . These MGCs were observed in limited amounts in only two out of the 18 samples. Both samples were obtained from LDPE implant sites (data not shown). Implantation in rats In contrast to the results in mice, in rats no major difference was observed between the three implants at day 98 . For all three samples, mature encapsulation of the implants and minimal to slight presence of infiltrate was observed [Table II and Figs. 2(D-F)]. Minimal indications for degeneration were observed using the positive control [Fig. 2(F)]. At days 3 and 7 the PVC-Sn resulted in a moderate degeneration and/or necrosis and an infiltrate with PMNs. No differences were observed between the LDPE and the PVC-Exp. MGCs were incidentally observed at the implant interface in seven out of 17 histological preparations collected at day 98 (data not shown). These cells were detected near all three types of implant materials.

\section{DISCUSSION}

Before clinical use of a biomaterial, the potential adverse effects of a material need to be determined. Although in vitro cytotoxicity assays do lack compensatory mechanisms that can modify an in vivo reaction, they are commonly used as an initial survey for new materials.

In vitro cytotoxicity assays to evaluate biomaterials are described in an international standard, thus implying that all assays can be performed in a similar way.[12] However, the standard describes the cytotoxicity assay only in general terms. The choice of cells, controls, animals, and endpoint has to be made by the investigator and should fit the biomaterial under investigation depending on the intended use of the material. To discuss some of the rationales behind the selection of parameters, we evaluated the cytotoxicity of three biomaterials by testing extracts of the test material, and conducting direct contact assays where either cells were seeded on the material or the material was placed on a cell monolayer. We used a mouse mesenchymal (fibroblast) cell line, which is mentioned in the EN/ISO standard 10993-5,[11] and a mouse epithelial cell line. In addition, one human keratinocyte cell line was included as such cells are expected to reflect human responses more closely. As expected, extracts of the negative and positive control materials showed no and a high cytotoxicity respectively. No cytotoxicity was observed using the PVC-Exp, although this material was especially manufactured to induce an intermediate response. In our assays, no differences were observed with regard to the sensitivity of the cell lines for the toxic residues. This sensitivity is crucial to measure intermediate toxic response. Others described differences in sensitivity of cell lines to various materials.[21-23] In addition, the selection of cell lines can be based on specific applications of the material under investigation. Freshly isolated Schwann cells can be used to determine the cytotoxic potential of materials used for nerve regeneration, fresh osteoblasts for bone substitutes, and keratinocytes for wound dressing materials.[24-26]

The direct contact assay indicated toxicity for the negative control material LDPE. If cells are seeded on a test material any reduction in metabolic activity (cytotoxicity) can be due to real toxicity by the release of toxic leachables, but also to intrinsic material properties resulting in reduced cell adherence and spreading. This latter mechanism is substantiated by our findings with the negative control material LDPE, which resulted in a reduction of metabolic activity of one of the cell lines. Therefore, if the materials under investigation are not specifically designed to support cell culture, the results should be considered very carefully. Others described the pre-coating of the material with e.g. poly-D-lysine 
or fibronectin,[27][28] thereby preventing an improper attachment and spreading of cells.

The direct contact assay can also be performed by placing materials on top of the cell monolayer. In our assay, the material covered one-seventh of the cell layer and no toxicity with the PVC-Exp was observed. This one-seventh coverage was based on earlier studies using the negative control material, in which we observed that a higher coverage affected the cell viability, probably by lack of nutrients or mechanical sheer (data not shown). In our opinion, it is difficult for a quantitative cellular assay to detect toxicity as local cell death, because a disc will only cover approximately $10 \%$ of the total cell surface. This percentage will probably lie within the range of the assay and the detection technique used, so that it would probably be difficult to discriminate between no toxic or low to intermediate toxic responses. In addition, our results with the positive control might indicate that the high level of toxicity observed was due to in situ extraction of toxic components. This is because the level of toxicity in the direct contact assay was comparable with the level of toxicity observed in the extraction assays. These limitations should be subject of further investigation.

Recently, other assays for in vitro biocompatibility testing have become available.[29-31] In these assays, cytokines as intermediates of an immune or inflammatory response are used as indicators for similar responses in vivo. These assays could circumvent any limitation of the direct contact assay. Although, also in these assays, toxic responses in terms of cell death need to be monitored. With the in vitro assays no conclusive toxic responses were detected for the intermediate material PVC-Exp. We also investigated the responses in vivo. All three materials were implanted in mice and rats. Both in mice and rats, the negative control was surrounded by a mature capsule with flattened cells at the implant interface, while the cellular infiltrate was moderate with minimal involvement of PMNs. However, a remarkable difference between mice and rats was detected with regard to the subcutaneous histopathological reaction of the positive control and the PVC-Exp. In mice, these samples could be clearly distinguished from the negative control by the histological reaction they had provoked at day 98 after implantation, while in rats, only minimal differences were observed. In mice, there was an appearance of activated cells at the implant interface, and in two out of six animals even a severe degeneration and necrosis was observed. This conclusion for intermediate toxicity is substantiated by the toxic responses observed at day 7 . In addition, in both mice and rats the positive control (PVC-Sn) induced an increase in cellular infiltrate containing PMNs, but again in mice, a more pronounced and prolonged inflammation composed of PMNs was detected. Hence, in our study the responses in mice as a whole were superior to identify toxic residues in implanted materials compared with the responses in rats. This is in contrast to the findings of Kidd et al.,[32] who observed a greater number of inflammatory cells (i.e. macrophages) in the peri-implant tissue in rats as compared with mice for expanded polytetrafluoroethylene implants.

One of the characteristics of the histopathological response to a subcutaneous implant is the formation of a so-called foreign body reaction in which MGCs are present.[2][33-36] These cells are formed during a foreign body reaction by fusion of macrophages which could not phagocyte the much larger biomaterial. These cells often persist for the lifetime of the implant. In our study, both in mice and rats, these cells were not abundantly present and no correlation was observed between the presence of MGCs and the cytotoxic potential of the material. The MGCs were somewhat more frequently observed at implantation sites in rats than in mice. This has been observed by others. [32][37] The mechanism for the difference in responses between mice and rats is yet 
unknown. However, it is not likely that the material of the implant itself is involved as several different materials were used.

In conclusion, when performing in vitro cytotoxicity testing, careful consideration should be given to the selection of controls and the read-out system. When conducting in vivo implantation studies, the selection of animals is of critical importance as in our study mice were more sensitive for toxic materials than rats.

\section{Acknowledgements}

The authors thank Dr. L. Berkenbosch, Solvay Draka, Enkhuizen, the Netherlands for providing the materials. Mrs. S.G.P.M. De Waal - Jacobs and Mr. C. Moolenbeek are acknowledged for their excellent technical assistance. 


\section{REFERENCES}

$1 \quad$ Williams D. Revisiting the definition of biocompatibility. Med Device Technol 2003; 14: 10-13. Links

2 Anderson JM. Biological responses to materials. Annu Rev Mater Res 2001; 31: 81-110. Links

3 Ratner BD, Bryant SJ. Biomaterials: where we have been and where we are going. Annu Rev Biomed Eng 2004; 6: 41-75. Links

$4 \quad$ Lavik E, Langer R. Tissue engineering: Current state and perspective. Appl Microbiol Biotechnol 2004; 65: 1-8. Links

5 Gambarini G, Andreasi-Bassi M, Bolognini G, Testarelli L, Nocca G, Ceccarelli L, Scatena R, Lupi A, Castagnola M. Cytotoxicity of a new endodontic filling material. Aust Endod J 2003; 29: 17-19. Links

6 Rogero SO, Malmonge SM, Lugao AB, Ikeda TI, Miyamaru L, Cruz AS. Biocompatibility study of polymeric biomaterials. Artif Organs 2003; 27: 424-427. Links

7 Kirkpatrick CJ, Bittinger F, Wagner M, Kohler H, Van Kooten TG, Klein CL, Otto M. Current trends in biocompatibility testing. Otto Proc Inst Mech Eng 1998; 212: 75-84. Links

Camps J, About I. Cytotoxicity testing of endodontic sealers: A new method. J Endod 2003; 29: 583-586. Links

Cadée JA, Van Luyn MJA, Brouwer LA, Plantinga JA, Van Wachem PB, de Groot CJ, den Otter W, Hennink WE. In vivo biocompatibility of dextran-based hydrogels. J Biomed Mater Res 2000; 50: 397-404. Links

Mendes SC, Reis RL, Bovell YP, Cunha AM, Van Blitterswijk CA, de Bruijn JD. Biocompatibility testing of novel starch-based materials with potential application in orthopaedic surgery: A preliminary study. Biomaterials 2001; 22: 2057-2064. Links

ISO. Biological Evaluation of Medical Devices, Part 1: Evaluation and Testing. EN/ISO 109931. Geneva, Switzerland; 2003.

ISO. Biological Evaluation of Medical Devices, Part 5: Tests for In Vitro Cytotoxicity. EN/ISO 10993-5. Geneva, Switzerland; 1999. Implantation. EN/ISO 10993-6. Geneva, Switzerland; 1994.

Peters K, Stumpf S, Kamp G, Schmidt H, Unger RE, Barth S, Kirkpatrick CJL. Validation of different cytotoxicity assays in endothelial cell cultures: Limits in testing cytotoxicty in vitro. The 7th World Biomaterials Congress, Sydney, Australia; 2004. 211-217. Links

Draye J, Delaey B, Van de Voorde A, Van den Bulcke A, De Reu B, Schacht E. In vitro and in vivo biocompatibility of dextran dialdehyde cross-linked gelatin hydrogel films. Biomaterials 1998; 19: 1677-1687. Links

Hanks CT, Wataha JC, Syn Z. In vitro models of biocompatibility: A review. Dent Mater 1996; 12: 186-193. Links

Pizzoferrato A, Ciapetti G, Stea S, Cenni E, Arciola CR, Granchi D, Savarino L. Cell culture methods for testing biocompatibility. Clin Mater 1994; 15: 173-190. Links

Boukamp P, Petrussevska RT, Breitkreutz D, Hornung J, Markham A, Fusenig NE. Normal keratinization in a spontaneously immortalized aneuploid human keratinocyte cell line. J Cell Biol 1988; 106: 761-771. Links by MTT assay. Biomaterials 1993; 14: 359-364. Links 
indices. J Mater Sci 1997; 8: 105-111. Links

Draye JP, Delaey B, Van de Voorde A, Van den Bulcke A, De Reu B, Schacht E. In vitro and in vivo biocompatibility of dextran dialdehyde cross-linked gelatin hydrogel films. Biomaterials 1998; 19: 1677-1687. Links

Park JC, Park BJ, Lee DH, Suh H, Kim DG, Kwon OH. Evaluation of the cytotoxicity of polyetherurethane (PU) film containing zinc diethyldithiocarbamate (ZDEC) on various cell lines. Yonsei Med J 2002; 43: 518-526. Links

Mitchell W, Matthew JB, Stone MH, Fisher J, Ingham E. Comparison of the response of human peripheral blood mononuclear cells to challenge with particles of three bone cements in vitro. Biomaterials 2003; 24: 737-748. Links biocompatibility of polypyrrole in vitro and in vivo. J Biomed Res 2004; 68: 411-422. Links

Liu BS, Yao CH, Chen YS, Hsu SH. In vitro evaluation of degradation and cytotoxicity of a novel composite as a bone substitute. J Biomed Mater Res 2003; 15: 1163-1169. Links

Liu Y, Zheng Shu X, Prestwich GD. Biocompatibility of disulfide-crosslinked hyaluronan films. Biomaterials 2005; 26: 4737-4746. Links

Van Kooten TG, Klein CL, Kohler H, Kirkpatrick CJ, Williams DF, Eloy R. From cytotoxicity to biocompatibility testing in vitro: Cell adhesion molecule expression defines a new set of parameters. J Mater Sci Mater Med 1997; 8: 835-841. Links

Newby CS, Barr RM, Greaves MW, Mallet AI. Cytokine release and cytotoxicity in human keratinocytes and fibroblasts induced by phenols and sodium dodecyl sulfate. J Invest Dermatol 2000; 115: 292-298. Links

Bailey LO, Washburn NR, Simon CG, Chan ES, Wang FW. Quantification of inflammatory cellular responses using real time polymerase chain reaction. J Biomed Mater Res A 2004; 69: 305-313. Links

Juste S, Lessard M, Henley N, Menard M, Halle JP. Effect of poly-L-lysine on macrophage activation by alginate-based microcapsules: Assessment using a new in vitro method. J Biomed Mater Res A 2005; 15: 389-398. Links

Kidd KR, Dal Ponte DB, Kellar RS, Williams SK. A comparative evaluation of the tissue responses associated with polymeric implants in the rat and mouse. J Biomed Mater Res 2002; 59: 682-689. Links

Salthouse TN. Some aspects of macrophage behavior at the implant interface. J Biomed Mater Res 1984; 18: 395-401. Links

Bergsma JE, Rozema FR, Bos RRM, Van Rozendaal AWM, De Jong WH, Teppema JS, Joziasse CAP. Biocompatibility and degradation mechanisms of predegraded and non-predegraded poly(lactide) implants. An animal study. J Mat Science Mater in Med 1995; 6: 715-724. Links

Butler K, Benghuzzi H, Tucci S. Tissue-implant response following soft tissue implantation of poly-L-lysine coated UHMW-polyethylene into adult male rats. Biomed Sci Instrum 2001; 37: 19-24. Links

Bonnema H, Popa ER, Van Timmeren MM, Van Wachem PB, De Leij LF, Van Luyn MJ. Distribution patterns of the membrane glycoprotein CD44 during the foreign-body reaction to a degradable biomaterial in rats and mice. J Biomed Mater Res 2003; 64: 502-508. Links

Khouw IM, van Wachem PB, Molema G, Plantinga JA, De Leij LF, van Luyn MJ. The foreign body reaction to a biodegradable biomaterial differs between rats and mice. J Biomed Mater Res 2000; 52: 439-446. Links 